\title{
Exurban sprawl increases the extinction probability of a threatened tortoise due to pet collections
}

\author{
Irene Pérez ${ }^{\mathrm{a}, \mathrm{b}, *}$, Alicia Tenza ${ }^{\mathrm{b}}$, José Daniel Anadón ${ }^{\mathrm{b}, \mathrm{c}}$, Julia Martínez-Fernández ${ }^{\mathrm{b}, \mathrm{d}}$, \\ Andrés Pedreño ${ }^{\mathrm{e}}$, Andrés Giménez ${ }^{\mathrm{b}}$ \\ a Center for the Study of Institutional Diversity, Arizona State University, Tempe, AZ, USA \\ b Departamento de Biología Aplicada, Ecología, Universidad Miguel Hernández, Elche, Alicante, Spain \\ ${ }^{c}$ Department of Conservation Biology, Estación Biológica de Doñana (EBD-CSIC), Sevilla, Spain \\ d Departamento de Ecología e Hidrología, Universidad de Murcia, Espinardo, Murcia, Spain \\ e Departamento de Sociología y Política Social, Univeridad de Murcia, Espinardo, Murcia, Spain
}

Keywords:

Harvesting

Human behavior

Species collection

System dynamics

Testudo graeca

Exurban sprawl

\begin{abstract}
A B S T R A C T
Human behavior is an important factor in understanding the impact of exurban sprawl (i.e. low-density rural home development) on native species. We studied the long-term effect of pet collection on populations of the threatened spur-thighed tortoise by residents of exurban areas in southeastern Spain. We built a system dynamic model using authors' own data and bibliographic data about tortoise population dynamics, the housing development dynamics, and the behavior of local residents toward this species. The model includes two submodels (spur-thighed population dynamics and households dynamics) interconnected through a tortoise collection submodel. Simulations showed that exurban intensity (i.e. size of a housing development) is essential in determining the intensity and speed of tortoise population decrease. Populations may become extinct due to collection in areas around medium to large housing developments (above 650 houses). Low housing development causes a considerable reduction of original population levels (more than 14\%). Environmental education program by itself, with the aim of reducing the willingness of new residents to keep tortoises in captivity, does not seem very effective. The quality and the speed with which the educational program is initialized are key factors in determining the effectiveness of the educational program. The scenarios simulation results suggest that the integration of policies of strong development constraints and educational programs are the most effective way in reducing the impact of exurban development on tortoise populations.
\end{abstract}

\section{Introduction}

Exurban sprawl represents one of the main factors impacting ecosystems and threatening biodiversity worldwide (Miller and Hobbs, 2002; Hansen et al., 2005). Exurban sprawl is low-density housing occurring in the fringes of cities and in rural areas distant from population centers. It is increasingly common in developed countries (Theobald, 2005; European Environment Agency (EEA), 2006). It has severe long-term consequences for wildlife, including reduction of richness, survival and reproduction of native species (Hansen et al., 2005). The proximate causes are habitat loss and fragmentation (Kluza et al., 2000; Riley et al., 2003, 2005), species introductions (Riley et al., 2005; Olden et al., 2006), alteration of ecological processes (e.g. changes of fire regimes and nutrient cycles) (Hansen et al., 2005), and direct antropogenic disturbances

\footnotetext{
* Corresponding author.

E-mail address: iperezib@asu.edu (I. Pérez).
}

(Gössling et al., 2004; Hansen et al., 2005; Jepson and Ladle, 2005, 2009; Peterson et al., 2005; O'Leary and Jones, 2006).

Attention is only just being focused on the impact of urbanized areas on wildlife (Miller and Hobbs, 2002; Cox, 2010; Sanderson and Huron, 2011) and the effects of exurban sprawl are not well understood (Hansen et al., 2005). Specially understudied are the effects of local residents' behavior on wildlife, though human-wildlife interactions are frequent in exurban areas. Some consequences of local residents' behavior are displacement of some species of wildlife due to human and pets disturbances, and changes on survival due to road kill, species collection, pet introduction, and domestication (e.g., Frid and Dill, 2002; Bautista et al., 2004; Peterson et al., 2005; O'Leary and Jones, 2006; Langston et al., 2007; Pérez et al., in press).

Traditionally, the study of human impact on wildlife, and its applicability to wildlife management, has been based on empirical studies. However, the often low quality of empirical data and the time and resources needed to obtain it can hinder decisions for wildlife management (Bennett et al., 2011). Thus, simulation 

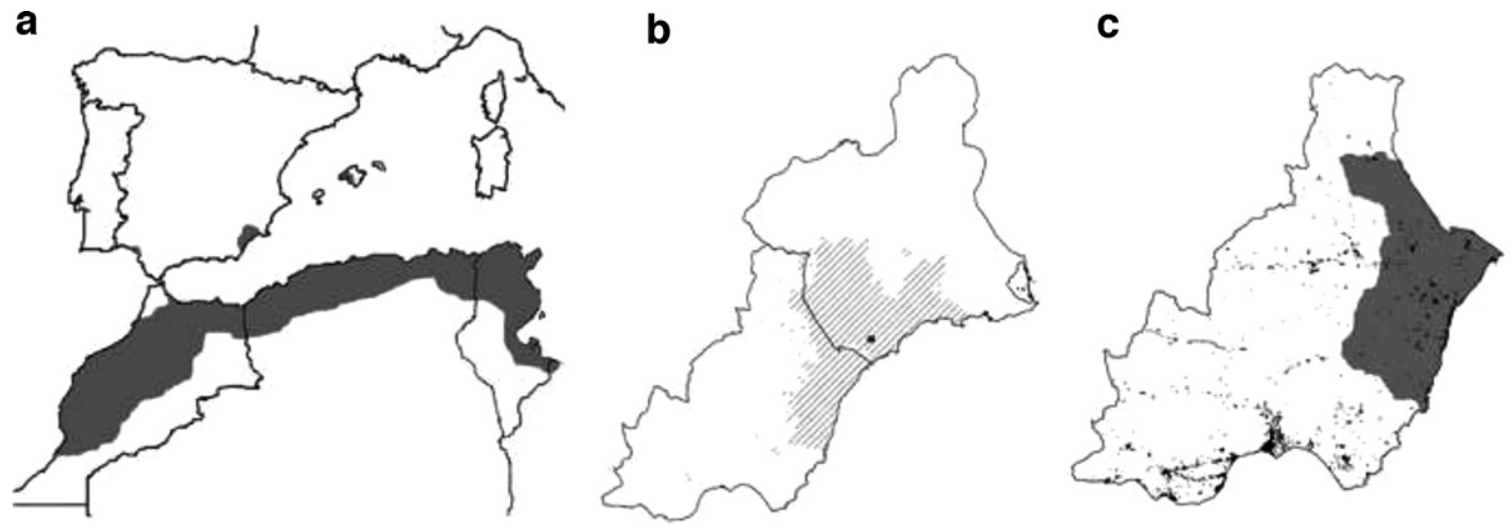

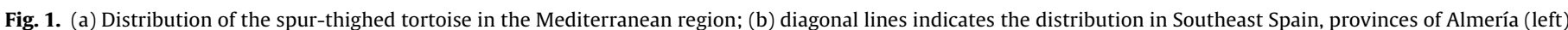


of Almería. Urbanized areas are highlighted in black.

models are proving to be very useful tool for studying humanwildlife conflicts and providing insights into more effective forms of wildlife management (Bennett et al., 2009). Modeling the residents' behavior on native species requires an understanding of the interlinked behavior of social and ecological systems. A social-ecological system consists of a bio-geo-physical unit and its associated social actors and institutions. Social-ecological systems are complex and adaptive with non-linear relationships between variables and long-term responses to changes; they are delimited by spatial or functional boundaries surrounding particular ecosystems and their problem context (Berkes and Folke, 1998; Glaser et al., 2008). Modeling the complex dynamics of social-ecological systems requires interdisciplinary research (Liu et al., 2007) to integrate the behavior of humans and the dynamics and responses of ecological systems.

In this paper we model pet collection of the spur-thighed tortoise (Testudo graeca graeca) by residents of exurban areas. We conducted our study in southeastern Spain, an area which supports the largest population of this species in Europe and where significant exurban sprawl has been taking place since the 1980s (Fernández, 2006; EEA, 2006; Mantecón, 2008; Camarero et al., 2009). Exurban development in this area has been usually associated with natural areas with high ecological and scenic values and mainly consists of the construction of housing developments. This has been causing an important loss of suitable habitat for the species (Giménez et al., 2006) and an increase in the practice of collecting these tortoises from wild populations to be kept as pets (Pérez et al., in press). Despite pet collection being prohibited, tortoises are collected by chance encounters around the urbanized areas (Pérez et al., 2004, in press). Tortoise collections by new residents are well intentioned. They collect tortoises because this species is seen as a pet and not as a wild animal, and to safeguard them from the threats of the wild (e.g. predators, resource shortages, being run over, etc.) (Pérez et al., 2010, 2011, in press). Previous research has estimated that $20-30 \%$ of households in exurban areas either were keeping or had kept tortoises in captivity, or are potential tortoise keepers (i.e. they would like to have pet tortoises) (Pérez et al., in press).

We aim to determine if the collection of wild tortoises may cause local extinction in areas where the presence of people has increased due to exurban sprawl by means of a dynamic simulation model. We formulate our model starting from social and ecological data collected using various methods (household surveys, ecological monitoring, and bibliography data). We integrate the various data sources in a system dynamic model, which interconnects the dynamic of a social (i.e. exurban household dynamics) and an ecological (i.e. spur-thighed population dynamics) system through humans' behavior (i.e. tortoises collection by local residents), which is moderated by socio-ecological factors (e.g. tortoise population density).

The objectives of this study are to (i) simulate the effects of collection on tortoise populations (ii) determine how different grades of exurban development, i.e. size of a housing development, affect the long-term dynamics of the spur-thighed tortoise, and (iii) simulate the effect of different management options. Based on simulation results, we provide some insights for wildlife management in exurban areas.

\section{Methods}

\subsection{Study system}

The spur-thighed tortoise is a long-lived terrestrial tortoise distributed in throughout North Africa and in small and isolated populations in southern Europe (Fig. 1). The species is categorized as vulnerable by the International Union for Conservation of Nature (IUCN, 2010). The main population of the spur-thighed tortoise in Europe inhabits semiarid coastal mountains in southeast Spain. Tortoises can be seen in those areas during springtime and the early summer, according to the activity patterns of the species (Pérez et al., 2002). Natural abundance values ranges from 0.05 to $20 \mathrm{indv} / \mathrm{ha}$, and are mainly related to climate (Anadón et al., 2009 2010). Late reproductive maturity, high and constant adult survival, low and variable juvenile survival and high fecundity determine its population dynamics (Hailey and Loumbourdis, 1990; DíazPaniagua et al., 2001).

Population dynamics of the species was studied by the authors through extensive fieldwork carried out since 1999 at the Cumbres de la Galera biological reserve (Sierra de la Carrasquilla, Murcia, Spain $37^{\circ} 32^{\prime} \mathrm{N}, 1^{\circ} 39^{\prime} \mathrm{W}$ ) (Fig. 1). The reserve has ca. 70 ha and the study area covered 35 ha. The reserve contains the optimum habitat for the species in terms of climate, relief and lithology (Anadón et al., 2006), and has a high density population of spur-thighed tortoise (20 indv/ha; Anadón et al., 2006, 2009).

The behavior of local residents toward the spur-thighed tortoise was obtained from a survey of residents of exurban areas of southeast Spain (Pérez et al., in press) (Fig. 1). This study was conducted in 2004 in the districts located within the spur-thighed tortoise's geographical range in the province of Almería, which comprises approximately $40 \%(133,300 \mathrm{ha})$ of the species' range in southeastern Spain (Anadón et al., 2010) (Fig. 1). Between 1991 and 2003, 
Table 1

Description of the variables and parameters of the spur-thighed tortoise dynamics submodel.

\begin{tabular}{|c|c|c|}
\hline Variable & Description & Units \\
\hline$A D$ & Adult tortoises & Tortoises \\
\hline Asurv & Adult survival & 1/Year \\
\hline Birth & Eggs eclosion & Tortoises/Year \\
\hline Clsize & Clutch size & Tortoises/Clutch \\
\hline Clutch & Clutches per year per female & Clutch/Year* Tortoises \\
\hline$D d$ & $\begin{array}{l}\text { Density dependence regulation of eggs } \\
\text { lay }\end{array}$ & - \\
\hline DeathA & Death adult tortoises (decrease adults) & Tortoises/Year \\
\hline DeathE & Death eggs (decrease eggs) & Tortoises/Year \\
\hline DeathH & Death hatchlings (decrease hatchlings) & Tortoises/Year \\
\hline DeathJ & Death juveniles (decrease juveniles) & Tortoises/Year \\
\hline EGG & Eggs & Tortoises \\
\hline Esurv & Eggs survival & 1/Year \\
\hline HATCH & Hatchlings $($ initial value $=899)$ & Tortoises \\
\hline$H-J$ & Flow of hatchlings to juveniles & Tortoises/Year \\
\hline Hsurv & Hatchlings survival & $1 /$ Year \\
\hline$J-A$ & Flow of juveniles to adults & Tortoises/Year \\
\hline Jsurv & Juvenile tortoises survival & $1 /$ Year \\
\hline JUV & Juvenile tortoises & Tortoises \\
\hline$k$ & Carrying capacity & Tortoises \\
\hline LayE & Eggs lay (increase eggs) & Tortoises/Year \\
\hline Maxden & Maximum density of tortoises & Tortoises/ha \\
\hline$P d A$ & Proportion of adults & 1/Year \\
\hline$p d E$ & Proportion of eggs & 1/Year \\
\hline$p d H$ & Proportion of hatch & 1/Year \\
\hline$P d J$ & Proportion of juveniles & 1/Year \\
\hline TotPOP & Wild tortoise population & Tortoises \\
\hline Range & Study range & ha \\
\hline Rep & $\begin{array}{l}\text { Percentage of females that reproduce } \\
\text { each year }\end{array}$ & Tortoises \\
\hline
\end{tabular}

urban and exurban areas in this area have increased by $38 \%$ and have covered an area of up to 2300 ha (Fig. 1).

\subsection{Model description}

The model was constructed using Vensim software (Ventana Systems, 1998). Fig. 2 illustrates the causal diagram. The model includes 11 level variables belonging to two submodels (spurthighed tortoise dynamics and households dynamics) interconnected through a tortoise collection submodel. A description of the model variables and parameters is given in Tables 1-3. For the construction of the causal diagram (Fig. 2), we used bibliography and extensive field data about the population dynamics of the species, the exurban sprawl dynamics, and the behavior of new residents toward the spur-thighed tortoise. We analyze how the collection of tortoises affects the emergent value of the level variables of our model.

\subsubsection{Spur-thighed tortoise dynamics submodel}

This submodel includes 4 level variables that represent different stages of the life cycle of tortoises: eggs (EGG), hatchlings (HATCH), juveniles (JUV) and adults (AD). HATCH, JUV, and $A D$ are characterized by their age range, survival rate, and reproductive capacity (Hailey and Loumbourdis, 1990). HATCH are non-reproductive individuals from 1 to 4 years old, and a low survival rate; JUV are non-reproductive individuals from 5 to 8 years old and higher survival rate than $H A T C H$; and $A D$ are reproductive individuals, older than 8 years old, and with the highest survival rate (Table 4 ). Survival changes the number of tortoises in each of these stocks. Wild populations have a sex ratio close to 1:1 (authors, unpub. data), and hence we consider that half of the $A D$ class may lay eggs (LayE). The percentage of females of a population that lay eggs each year is $93 \%$ (Díaz-Paniagua et al., 2001) (Rep; Table 4). Females have the ability to produce more than one clutch per year (Clutch) and they lay more than one egg per clutch (Clsize) (Díaz-Paniagua et al., 1997,
Table 2

Description of the variables and parameters of the households dynamics submodel.

\begin{tabular}{|c|c|c|}
\hline Variable & Description & Units \\
\hline Death & Captive tortoise mortality & 1/Year \\
\hline Dissatisfied & $\begin{array}{l}\text { Flow of satisfied (SATH) to unsatisfied } \\
\text { households }\end{array}$ & Households/Year \\
\hline Maxh & Maximum number of households & Households \\
\hline Missing & Captive tortoises missed & 1/Year \\
\hline Nwant & $\begin{array}{l}\text { Flow of occupied households to } \\
\text { households that do not want tortoises }\end{array}$ & Households/Year \\
\hline NWANTH & Households that do not want tortoises & Households \\
\hline $\mathrm{OCCH}$ & Occupied households & Households \\
\hline Occupation & $\begin{array}{l}\text { Occupation of empty households } \\
\text { (increase occupied households; OCCH) }\end{array}$ & Households/Year \\
\hline Pnw & Proportion of households & $1 /$ Year \\
\hline Potoccupa & Occupation rate of households & 1/Year \\
\hline Pwant & $\begin{array}{l}\text { Percentage of households that want } \\
\text { tortoises }\end{array}$ & 1/Year \\
\hline Remh & Empty households available each year & Households/Year \\
\hline Remratio & $\begin{array}{l}\text { Occupation rate when unoccupied } \\
\text { households are less than } 100 \\
\text { households }\end{array}$ & 1/Year \\
\hline Sat & $\begin{array}{l}\text { Unsatisfied households that became } \\
\text { satisfied households each year }\end{array}$ & Households/Year \\
\hline SATH & Satisfied households & Households \\
\hline Satratio & $\begin{array}{l}\text { Rate in which unsatisfied households } \\
\text { became satisfied households }\end{array}$ & 1/Year \\
\hline Toth & Total occupied households & Households \\
\hline UNSATH & Unsatisfied households & Households \\
\hline Vacancy & Empty households & Households \\
\hline Want & $\begin{array}{l}\text { Flow of occupied households to } \\
\text { unsatisfied households }\end{array}$ & Households/Year \\
\hline
\end{tabular}

2001; Mora et al., 2006) (Table 4). The model includes a densitydependent dynamic of the population that regulates LayE (Table 4):

LayE $=$ Clsize $*$ Clutch $* \operatorname{Rep} *(1-A D / k) ;$ where $k$ is the

carrying capacity:

$k=$ Maxden ${ }^{*}$ Range; where Maxden is the maximum density of tortoises and Range is the study range.

Table 3

Description of the variables and parameters of the tortoise collection submodel,

\begin{tabular}{|c|c|c|}
\hline Variable & Description & Units \\
\hline CAPAD & Captive adult tortoises & Tortoises \\
\hline САРНАТСH & Captive hatchlings & Tortoises \\
\hline CAPJUV & Captive juveniles & Tortoises \\
\hline TotCAPРOP & $\begin{array}{l}\text { Total population of captive } \\
\text { tortoises }\end{array}$ & Tortoises \\
\hline Demand & Tortoises required per year & Tortoises/Year \\
\hline Dratio & Tortoises demand rate & 1/Year \\
\hline Effort & $\begin{array}{l}\text { Effort a household apply in } \\
\text { searching for tortoises }\end{array}$ & Hour/(Households *Year) \\
\hline Encounter & $\begin{array}{l}\text { Tortoises found per unsatisfied } \\
\text { households per year }\end{array}$ & Tortoises/Year \\
\hline HarvA & $\begin{array}{l}\text { Adult tortoises harvested (decrease } \\
\text { AD) }\end{array}$ & Tortoises/Year \\
\hline Harvesting & Tortoises harvested & Tortoises/Year \\
\hline HarvH & Hatchlings harvested (decrease $\mathrm{H}$ ) & Tortoises/Year \\
\hline HarvJ & $\begin{array}{l}\text { Juvenile tortoises harvested } \\
\text { (decrease J) }\end{array}$ & Tortoises/Year \\
\hline Numtor & $\begin{array}{l}\text { Number of tortoises required per } \\
\text { unsatisfied household }\end{array}$ & Tortoises/Households \\
\hline Pencounter & $\begin{array}{l}\text { Probability of encounter of } \\
\text { tortoises }\end{array}$ & Tortoises/Hour \\
\hline Range & Study range & ha \\
\hline Satisfiableh & $\begin{array}{l}\text { Unsatisfied households that may } \\
\text { be satisfied each year }\end{array}$ & Households/Year \\
\hline Toteffort & $\begin{array}{l}\text { Effort unsatisfied household apply } \\
\text { in searching for tortoises }\end{array}$ & Hour/Year \\
\hline Torden & Tortoise population density & Tortoises/ha \\
\hline
\end{tabular}




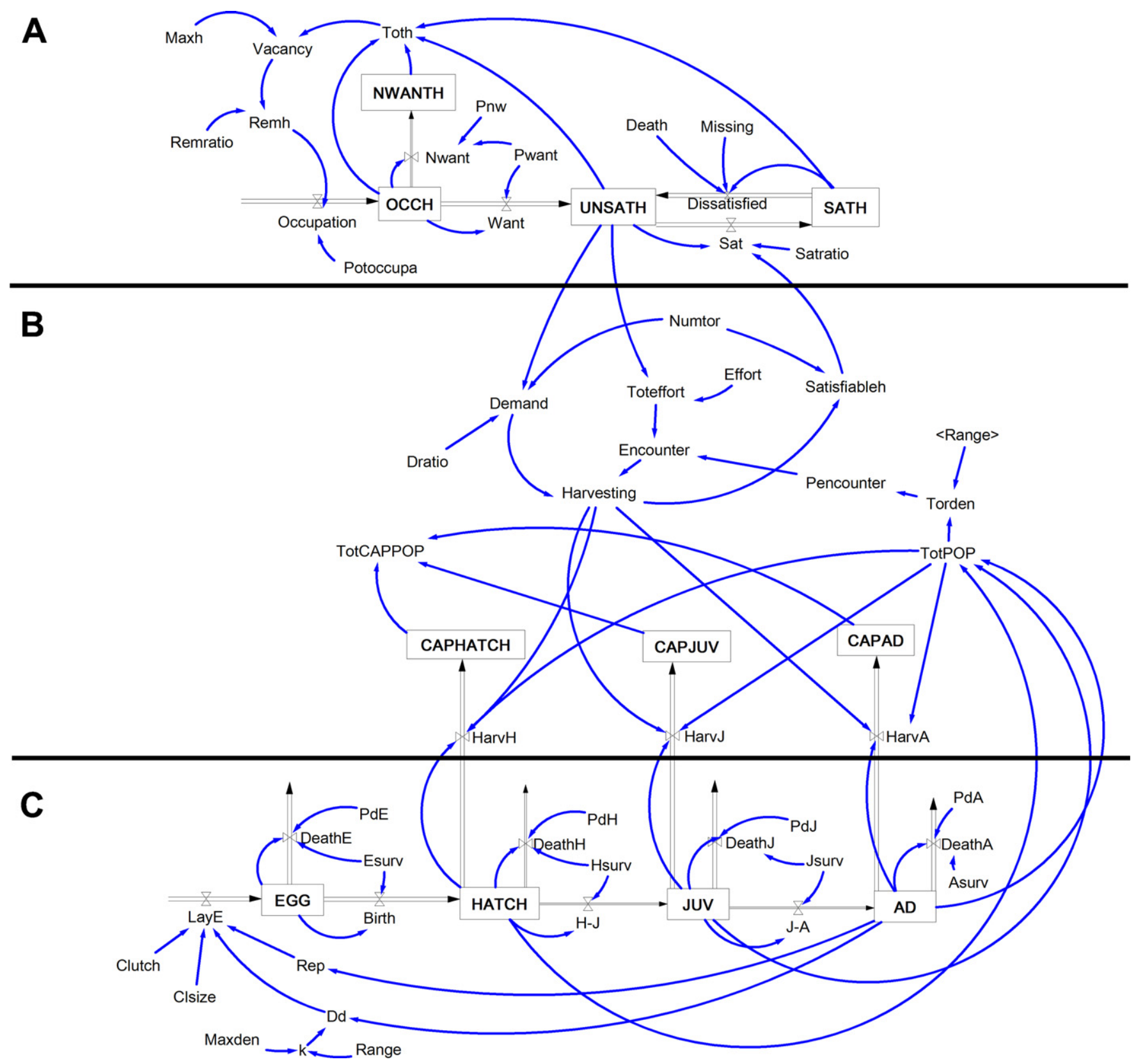

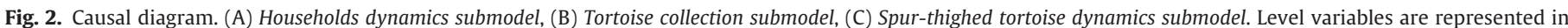



\subsubsection{Households dynamics submodel}

The submodel of households simulates the occupation dynamic of households in an exurban area within the spur-thighed tortoise distribution area. Exurban sprawl intensity is expressed by the maximum number of households available at the beginning of the simulation (Maxh). Our study unit is the household. With a certain rate households are occupied by new residents (Potoccupa) (Table 4). Of those occupied households (OCCH), a proportion (Pwant; Table 4) are households with occupants who want to have tortoises (UNSATH), and the remainder do not (NWANTH). UNSATH are unsatisfied households, that is, those households that do want tortoises in captivity but they do not have one. They may become a satisfied household $(S A T H)$ if they collect the number of tortoises required (Numtor; Table 4). SATH may return to UNSATH if captive tortoises die (Death) or are lost (Missing). UNSATH may collect tortoises depending on the density of tortoises and the number of hours they spent searching for tortoises. These dynamics are expressed in the tortoise collection submodel (see below).

\subsubsection{Tortoise collection submodel}

The spur-thighed tortoise dynamic and households submodels are connected by feedbacks related with the density of tortoises and the willingness of households to have tortoises. Each unsatisfied household (UNSATH) may collect tortoises, until they have successfully collected all the tortoises they would like (Numtor). Tortoise collection depends on the effort the household applies in searching for tortoises (hours per year) (Effort) and the probability of encountering a tortoise (Pencounter) based on the density of tortoises in the area (Torden) (Table 4). The amount of tortoises collected (Harvesting) is the minimum value between the tortoises that can be found in the wild (Encounter $=$ Pencounter ${ }^{*}$ Toteffort) and the amount of tortoises wanted by households (Demand $=U N S A T H^{*}$ Numtor $)$. We 
Table 4

Parameter values used in the default model.

\begin{tabular}{lcl}
\hline Parameter & Value & Reference \\
\hline Asurv & 0.98 & Sanz-Aguilar et al. (2011) \\
Clutch & 1.636 & Authors (unpub. data) \\
Clsize & 2.58 & Authors (unpub. data) \\
Death & 0.22 & Pérez et al. (in press) \\
Dratio & 1 & - \\
Effort & 1 & - \\
Esurv & 0.782 & Díaz-Paniagua et al. (1997) \\
Hsurv & 0.20 & Sanz-Aguilar et al. (2011) \\
Jsurv & 0.79 & Sanz-Aguilar et al. (2011) \\
Maxh & 3000 & Aliaga (2008) \\
Maxden & 20 & Anadón et al. (2009) \\
Missing & 0.35 & Pérez et al. (2010, in press) \\
Potoccupa & 100 & - \\
Pencounter & - & Anadón et al. (2009) \\
Range & 100 & - \\
Remratio & 1 & - \\
Rep & 0.933 & Díaz-Paniagua et al. (2001) \\
Satratio & 1 & - \\
Numtor & 3 & Pérez et al. (2010, in press) \\
Pwant & 0.26 & Pérez et al. (2010, in press) \\
\hline
\end{tabular}

consider that $H A T C H, J U V$, and $A D$ have the same encounter probability (Sanz-Aguilar et al., 2011). As a consequence, a proportional number to the density of $H A T C H, J U V$, and $A D$ are harvested and increase the stock of tortoises that are maintained in captivity (TotCAPPOP, CAPHATCH, CAPJUV, CAPAD).

\subsection{Model parameters}

In the Cumbres de la Galera biological reserve (Fig. 1), from May 2005 to May 2006, authors X-rayed radio-tracked females every 2 weeks during the spring activity season in order to estimate the number of clutches (Clutch) and the total number of eggs per clutch (Clsize) laid each year (Mora et al., 2006) (Table 4). The survival rate of HATCH, JUV and AD (Hsurv, Jsurv, and Asurv) was obtained from a study carried out in the same population from 1999 to 2009 by means of capture-recapture and multistate models (Sanz-Aguilar et al., 2011) (Table 4). We used values of egg survival (Esurv) and Rep from studies carried out in a population in southwest Spain (DíazPaniagua et al., 1997, 2001) (Table 4). The default model considers a maximum density of tortoises (Maxden) of 20 tortoises/ha (Anadón et al., 2009, 2010).

Parameters of the interactions between new residents with the species within the households dynamics submodel (Pwant, Death, Missing, and Numtor) were obtained from a survey in which Pérez et al. (in press) asked residents from exurban areas in southeast Spain about the practices of collecting and keeping tortoises in captivity (Table 4). We consider no delays in the flow of unsatisfied (UNSATH) to satisfied households (SATH); thus Satratio is settled to 1 (Table 4).

Although there is no specific data available on the size of housing developments in the species' range, existing information indicates that housing development sizes vary from few tens to three thousands of households ( mean $=1236, \mathrm{sd}=885$ ) (Díez de Revenga et al., 2006; Aliaga, 2008). The model considers a Maxh of 3000 households, i.e. the maximum size of housing developments in southeastern Spain (Díez de Revenga et al., 2006; Aliaga, 2008), and that 100 households are occupied each year (Potoccupa). If there are less than 100 available households, they are occupied in one year (Remratio).

Anadón et al. (2009) estimated the relationship between the absolute (tortoises/ha) and relative (tortoises found per person and per hour) abundance of tortoises in southeast Spain. We used this estimation to determine the probability of new residents encountering tortoises (Pencounter). Local residents find tortoises
Table 5

Parameters and their ranges used in the sensitivity analysis and relative sensitivity coefficients.

\begin{tabular}{lcclr}
\hline Parameter & Range & Increment & TotPOP & TotCAPPOP \\
\hline Effort & $0.5-1.5$ & 0.005 & 0 & -0.0348 \\
Maxden & $10-30$ & 0.1 & 0 & 0.4876 \\
Maxh & $1500-4500$ & 15 & 0 & -0.0092 \\
Numtor & $1.5-4.5$ & 0.015 & 0 & -0.0099 \\
Pwant & $0.1-0.4$ & 0.001 & 0 & -0.0440 \\
Potoccupa & $50-150$ & 0.5 & 0 & -0.0402 \\
\hline
\end{tabular}

by chance encounter while hiking, walking or riding around urbanized areas, and not by intentional search. Thus, local residents expend few time in areas where they have a chance to find a tortoise. We assume that each household spent $1 \mathrm{~h} /$ year in areas where they have chances to find a tortoises (Effort) and that they may collect tortoises in an area of 100 ha around the urbanized area (Range). To avoid lags in the model, we consider that the demand of tortoises (Demand) is covered immediately while there are wild tortoises (Dratio).

The unit of time in the simulations was one year and the time step 0.25 years. We ran the model for 100 years. The model is initialized with an unoccupied exurban area settled in an area with a stable population of Testudo graeca. For this, we settled the level variables of the households dynamics submodel to zero of the spur-thighed tortoise dynamics submodel to equilibrium using the reproductive and survival parameters showed in Table 4. This allows us to simulate, under different assumptions of exurban intensity, the effect of collecting tortoises by new residents on wild populations of the spur-thighed tortoise if an area is urbanized.

\subsection{Model testing}

Model testing was established through a dimensional consistency test, extreme condition tests, and sensitivity analysis (Barlas, 1996). In the sensitivity analysis, we vary the value of the main model parameters 50\% above and below the default value (Table 5). For each parameter, the model is run 200 times. We look at the variation in the wild and captive populations (TotPOP and TotCAPPOP) and calculate the relative sensitivity coefficients.

\subsection{Model scenarios}

We use our model to explore the long-term effects of several constraints scenarios that might contribute to the conservation of wild populations of the spur-thighed tortoise in exurban areas. In particular, we aim to simulate how (1) urban development control, expressed as size limits on housing developments, and (2) changes in residents' behavior, through an environmental education program, might affect the impact of exurban sprawl.

To answer these questions we analyzed 33 different scenarios in which we control: (i) the housing development's size (Maxh), (ii) the proportion of residents willing to have tortoises (Pwant) and the number of tortoises that they want (Numtor), and (iii) both, the housing development's size and the behavior of residents (Table 6). Within the first group we analyzed three scenarios of weak, moderate, and strong levels of control of housing developments. For this, we reduced Maxh to the percentile 75 (weak development constraint, $W D C$ ), percentile 25 (moderate development constraint, $M D C$ ), and percentile 1 (strong development constraint, $S D C$ ) of the housing developments size in southeastern Spain (Díez de Revenga et al., 2006; Aliaga, 2008) (Table 6).

Within the second group of scenarios, we included a variable with the value of zero if an educational program is deactivated and one if the program is activated. This variable affects the willingness of households to have tortoises in captivity. We consider 12 
Table 6

Model scenarios. Highlighted in bold are the parameters value that differ from the default model.

\begin{tabular}{|c|c|c|c|c|c|}
\hline Scenario & Delay & Educational program & Maxh & Numtor & Pwant \\
\hline \multicolumn{6}{|l|}{ Control of housing development's size } \\
\hline Weak development constraint (WDC) & 0 & 0 & 1500 & 3 & 0.26 \\
\hline Moderate development constraint (MDC) & 0 & 0 & 650 & 3 & 0.26 \\
\hline Strong development constraint (SDC) & 0 & 0 & 75 & 3 & 0.26 \\
\hline \multicolumn{6}{|l|}{ Control of the behavior of residents } \\
\hline No delay-low efficiency educational program (NDLEP) & 0 & 1 & 3000 & 3 & 0.13 \\
\hline Low delay-low efficiency educational program (LDLEP) & 5 & 1 & 3000 & 3 & 0.13 \\
\hline Moderate delay-low efficiency educational program (MDLEP) & 15 & 1 & 3000 & 3 & 0.13 \\
\hline High delay-low efficiency educational program (HDLEP) & 30 & 1 & 3000 & 3 & 0.13 \\
\hline No delay-moderate efficiency educational program (NDMEP) & 0 & 1 & 3000 & 1 & 0.13 \\
\hline Low delay-moderate efficiency educational program (LDMEP) & 5 & 1 & 3000 & 1 & 0.13 \\
\hline Moderate delay-moderate efficiency educational program (MDMEP) & 15 & 1 & 3000 & 1 & 0.13 \\
\hline High delay-moderate efficiency educational program (HDMEP) & 30 & 1 & 3000 & 1 & 0.13 \\
\hline No delay-high efficiency educational program (NDHEP) & 0 & 1 & 3000 & 1 & 0.001 \\
\hline Low delay-high efficiency educational program (LDHEP) & 5 & 1 & 3000 & 1 & 0.001 \\
\hline Moderate delay-high efficiency educational program (MDHEP) & 15 & 1 & 3000 & 1 & 0.001 \\
\hline High delay-high efficiency educational program (HDHEP) & 30 & 1 & 3000 & 1 & 0.001 \\
\hline \multicolumn{6}{|l|}{ Control of housing development's size and the behavior of residents } \\
\hline WDC-LDLEP & 5 & 1 & 1500 & 3 & 0.13 \\
\hline WDC-LDMEP & 5 & 1 & 1500 & 1 & 0.13 \\
\hline WDC-LDHEP & 5 & 1 & 1500 & 1 & 0.001 \\
\hline WDC-HDLEP & 30 & 1 & 1500 & 3 & 0.13 \\
\hline WDC-HDMEP & 30 & 1 & 1500 & 1 & 0.13 \\
\hline WDC-HDHEP & 30 & 1 & 1500 & 1 & 0.001 \\
\hline MDC-LDLEP & 5 & 1 & 650 & 3 & 0.13 \\
\hline MDC-LDMEP & 5 & 1 & 650 & 1 & 0.13 \\
\hline MDC-LDHEP & 5 & 1 & 650 & 1 & 0.001 \\
\hline MDC-HDLEP & 30 & 1 & 650 & 3 & 0.13 \\
\hline MDC-HDMEP & 30 & 1 & 650 & 1 & 0.13 \\
\hline MDC-HDHEP & 30 & 1 & 650 & 1 & 0.001 \\
\hline SDC-LDLEP & 5 & 1 & 75 & 3 & 0.13 \\
\hline SDC-LDMEP & 5 & 1 & 75 & 1 & 0.13 \\
\hline SDC-LDHEP & 5 & 1 & 75 & 1 & 0.001 \\
\hline SDC-HDLEP & 30 & 1 & 75 & 3 & 0.13 \\
\hline SDC-HDMEP & 30 & 1 & 75 & 1 & 0.13 \\
\hline SDC-HDHEP & 30 & 1 & 75 & 1 & 0.001 \\
\hline
\end{tabular}

scenarios with the educational program switch on which represents different grades of outputs of the program (Table 6). To determine the outputs of the program we considered: (1) the delay (number of years) in the application of the educational program; and (2) the efficiency of the educational program. We considered four values for the delay parameter from zero (no delay) to 30 (high delay) years. A delay of zero means that the program starts when the housing development is constructed. A delay of 30 years (the program starts after 30 years of the construction of the housing development) reflects what would be the effect on tortoise population if an educational program is developed in the older housing developments of the study area. The efficiency of the program is measured changing the value of two parameters: Pwant and Numtor; resulting in three combinations, from low to high efficiency educational program. In the low efficiency education program, the recipients of the program are just some of the local residents. In this scenario, Pwant is reduced to 0.13 . In the moderate efficiency educational program, we not only reduce Pwant, but also Numtor from three to one, meaning that the recipients of the program are all the local residents but its efficiency is moderate (i.e. $13 \%$ of local residents would keep a maximum of one pet tortoise). In the high efficiency educational program, Pwant is reduced to 0.001 and $\mathrm{Num}$ tor to one (i.e. almost none of the local residents would keep pet tortoise) (Table 6).

Within the third group of scenarios, we combine the effect of controlling the housing development's size and the application of an educational program. We analyzed 18 scenarios in which we combine a weak, moderate, and strong development constraint with a low, moderate, and high efficiency educational program with low and high delay (Table 6).

\section{Results}

\subsection{Default model}

Figs. 3 and 4 show the emergent values of the level variables and key variables of our default scenario. During the first years of the simulation, Harvesting increases sharply as households are being occupied and when the abundance of tortoises (TotPOP) and the probability of encounter tortoises (Pencounter) are high. Harvesting causes the tortoise population drop until the population becomes extinct (at year 65 totPOP became zero).

Satisfied households (SATH) reaches a maximum around year $15-17$, when $13 \%$ of the households that want tortoises are satisfied. After that threshold, the Pencounter decrease to half of the initial value as a result of population decrease (at that time step, tortoise population has decreased approximately to half). At year 30 the Pencounter is 0.01 , making Harvesting and SATH decrease to low values and keep a high Demand of tortoises. At year 51, SATH is zero because the number of harvested tortoises are less than the captive tortoises that leave the system through Death or Missing.

\subsection{Model testing}

Extreme condition tests show that the model behaves as expected under extreme conditions. For example, the absence of households desiring tortoises (Pwant) leads to the absence of harvesting (Harvesting) and unsatisfied households (UNSATH); the absence of Harvesting leads to the absence of hatchling, juvenile, and adult harvesting; the absence of tortoises required (Numtor) 

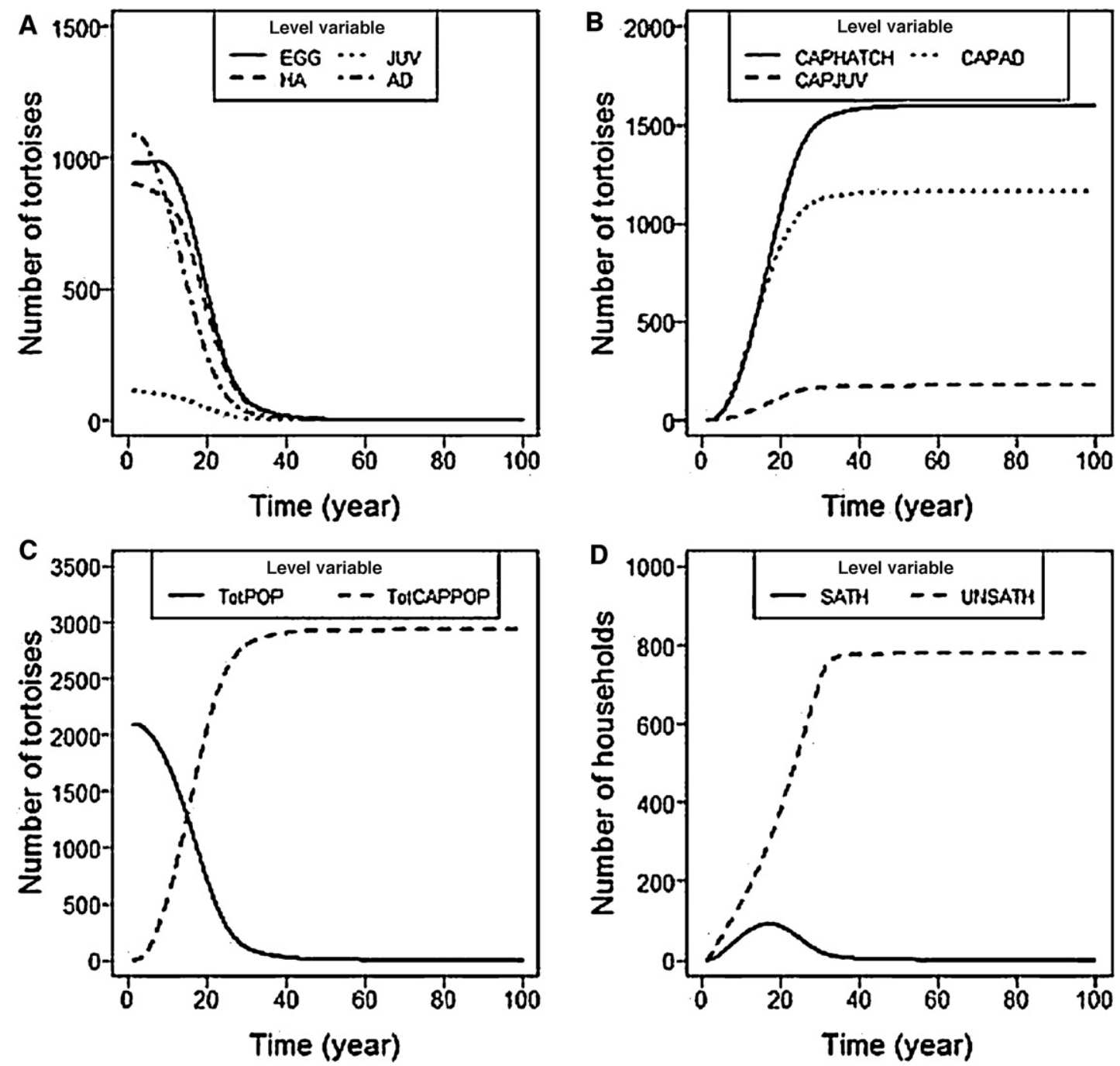

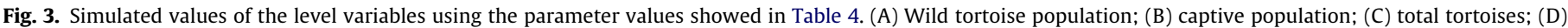
households.

leads to the absence of Demand and Harvesting; the absence of tortoises (TotPOP) leads to the absence of Encounter; and the absence of Maxh leads to the absence of households occupation (Occupation).

Sensitivity analysis showed variations in the main parameter values of the model do not generate high variations in the level variables TotPOP and TotCAPOP(Fig. 5, Table 5). These level variables show a low sensitivity to variation in the value of the parameters Numtor and Maxh. Pwant, Potoccupa and Effort have a higher sensitivity during the first years, when the variation range is higher. However, they have the same trend as the default model and the variation decreases with time. The level variables analyzed showed a higher sensitivity to variation of the parameter Maxden. This parameter defines the carrying capacity $(K)$ and affects tortoises' reproduction. At the beginning, the sensitivity of TotPOP is higher than at the end of the simulation, whereas for TotCAPOP the sensitivity increases as the simulation runs. Thus TotCAPOP highly depends on the density of wild tortoises.

\subsection{Analysis of scenarios}

The emergent values of tortoise population (TotPOP) changes in the scenarios considered (Fig. 6). As we can see in Fig. 6A, weak development constraints (above 1500 houses) are not able to reverse the decreasing trend, after the simulation only 1 individual remained in the wild population. With moderate development constraints (650 houses), tortoise populations do not become extinct at the end of the simulation, although they show a decreasing trend and suffer a reduction of $97 \%$ in the number of individuals. Only strong development constraints ( 75 houses) allow the persistence of tortoise populations, although at the end of the simulation the number of individuals reduced by $14 \%$.

Within the educational program scenarios, the tortoise population do not become extinct in the scenarios in which a high efficiency educational program is instituted within the first 5 years of the initiation of housing development (NDHEP and LDHEP) (Fig. 6). However, with a high efficiency and low delay (5 years) educational program (LDHEP), tortoise populations suffer a reduction of $68 \%$. In the scenario of no delay and high efficiency (NDHEP), the population reduction is of $1 \%$ (Fig. 6D). When we consider the scenarios of moderate efficiency of the educational program but with a delay of 15 years or more, total population (totPOP) became zero. This occurs at year 86 and 66 of the simulation (a delay in the population extinction of 21 and 1 years from the default model), respectively (Fig. 6C). A high efficiency educational program but with a long delay in its application also causes the extinction of tortoise populations at year 66 (Fig. 6D). In the rest of the scenarios, only 2-5 individuals remain in the wild population.

When we combine housing development control with the development of an educational program (Fig. 7), we found that the tortoise population becomes extinct in the scenarios in which a 

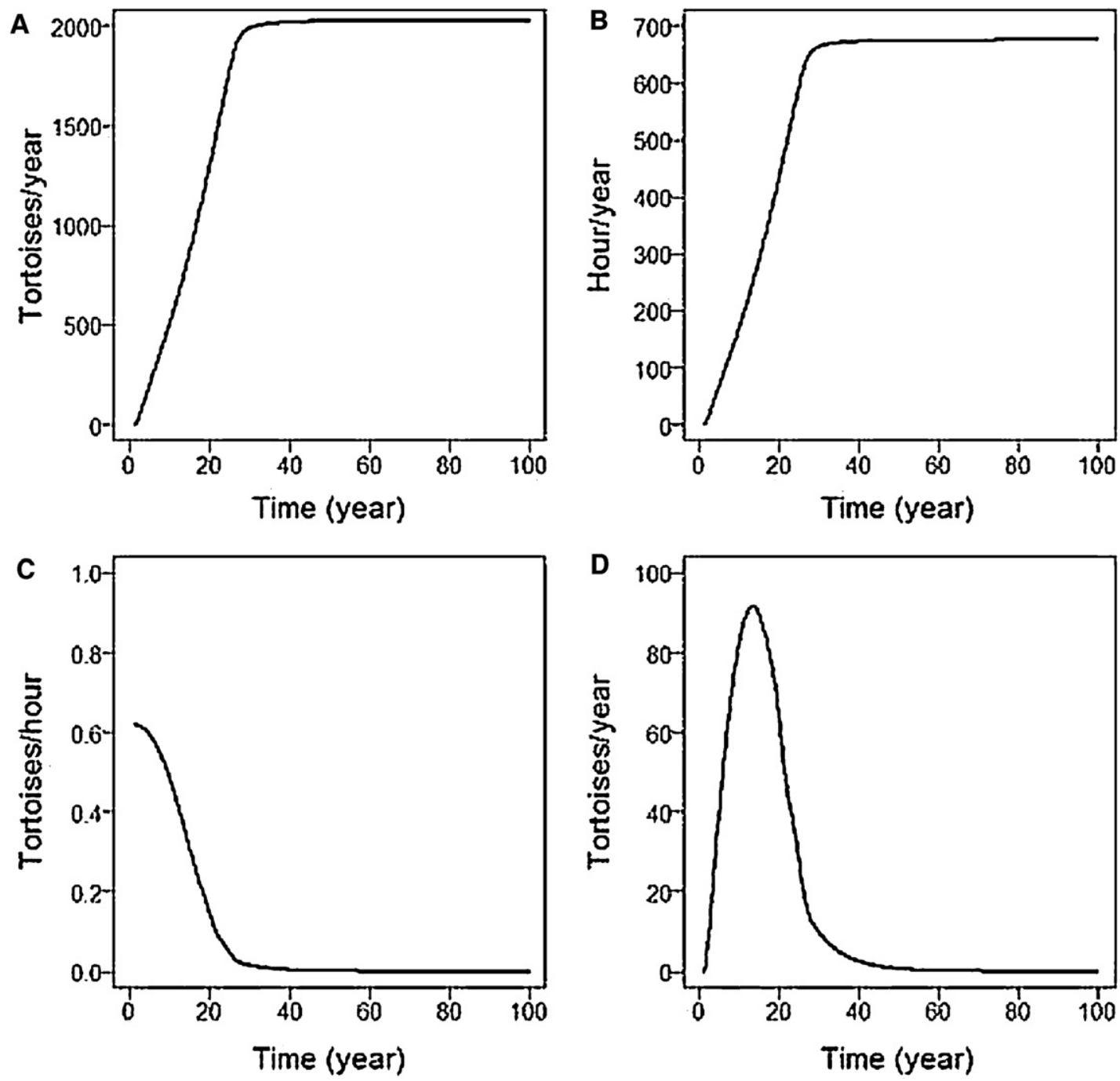

Fig. 4. Simulated values of the variables Demand (A), Toteffort (B), Pencounter (C), Harvesting (D) using the parameter values showed in Table 4.

weak development constraints is combined with a high delay educational program (WDC-HDLEP, WDC-HDMEP, WDC-HDHEP). With moderate development constraints, and with low development constraints accomplished with a low delay educational program, tortoise populations do not become extinct, although at the end of the simulation the number of individuals reduced by up to $99 \%$. This reduction is of $67 \%$ in the scenarios of high efficiency and low delay educational program (WDC-LDHEP and MDC-LDHEP). Again, only strong development constraints allow the persistence of tortoise population, with a population reduction of $7-8 \%$ to $14 \%$ in the scenarios in which a low or high delay educational program is instituted, respectively.

\section{Discussion}

Our simulations indicate that the behavior of exurban residents threatens wild populations of the spur-thighed tortoise. The species is very sensitive to pet collection, which may cause a significant population reduction in medium to high-size urbanized areas in the mid- to long-term. This population decrease may cause the local extinction of isolated populations, of a size up to 100 ha accordingly to our simulations, and consequently an important population decrease in larger populations. Thus, our results show that exurban sprawl not only has the immediate impact of habitat destruction but that the effects on biodiversity will continue for several decades due to local residents' behavior. To our knowledge, this study is one of the few attempts to quantify the effects of residents' behavior in exurban areas and it supports the assertion that local residents' behavior could be an important threat to native wildlife (Hansen et al., 2005).

Exurban intensity, measured in this study as the size of a housing development, is a key factor determining the intensity and speed of tortoise population decrease. Our simulations suggest that housing development projects with above 1500 houses may cause the local extinction of the species. Existing information indicates that this threshold size is slightly above the mean size of current housing developments in southeastern Spain, although the largest housing projects clearly exceed it (Aliaga, 2008). A moderate development intensity (around 650 houses), reached by most of the housing developments in southeastern Spain, causes a reduction of up to $97 \%$ of the tortoise population. Low housing developments, although do not cause the local extinction of the species, causes a considerable reduction of original population levels (more than $14 \%$ ) and tortoise population continues having a decreasing trend at the end of the simulation (100 years). This decrease makes populations much more vulnerable to other common impacts in exurban areas, such as accidental or intentional fires, road kills, predation by introduced pets, or any source of environmental stochasticity 

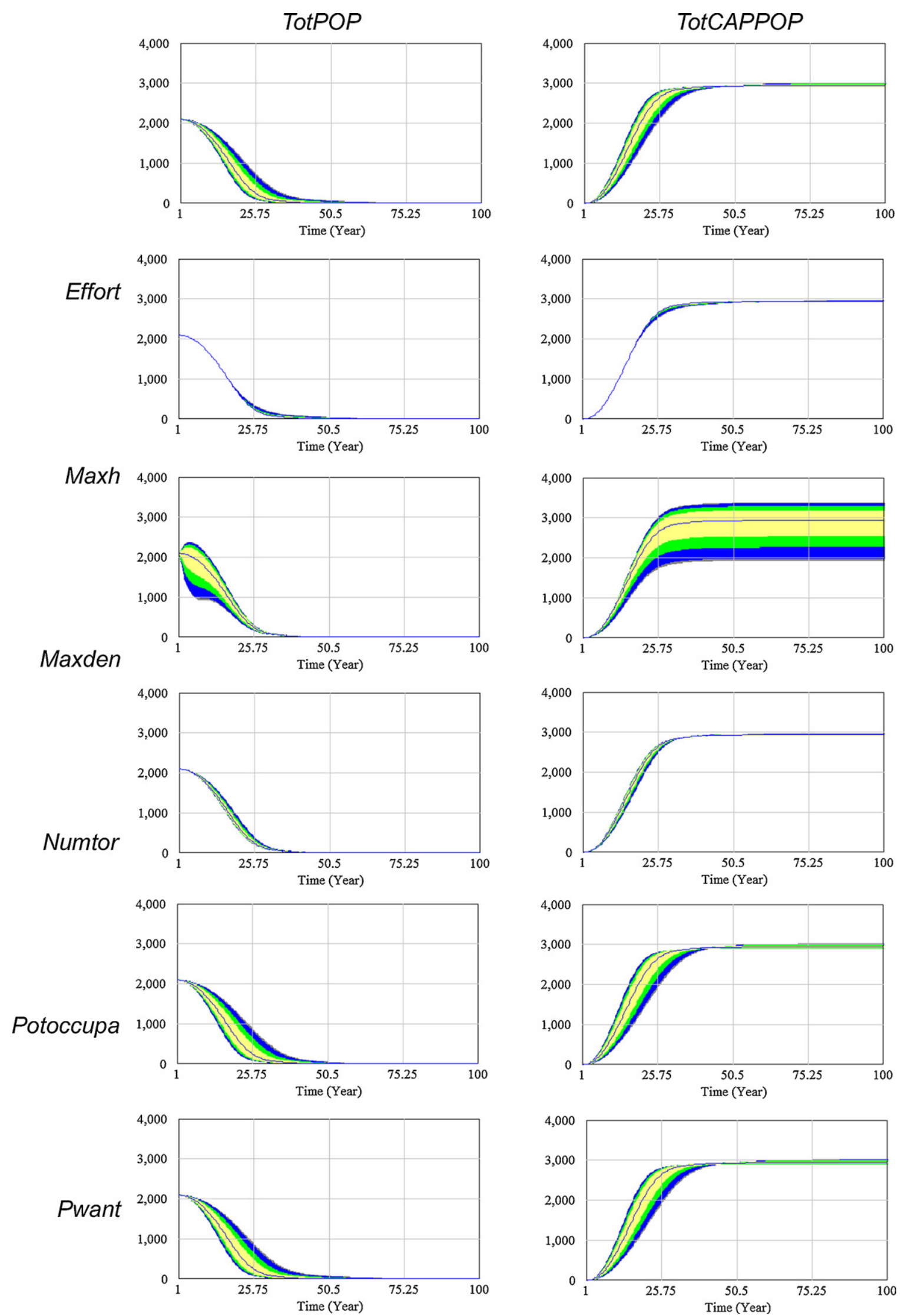



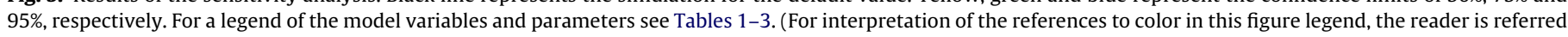
to the web version of the article.) 



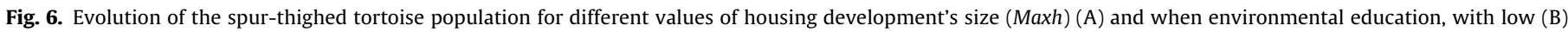

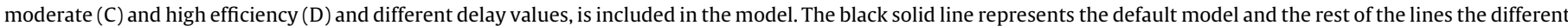
scenarios considered (Table 6).

(Hansen et al., 2005; Boarman and Sazaki, 2006; Sanz-Aguilar et al., 2011).

Our results support those studies showing that wildlife populations with very high survival rates of adults, like terrestrial tortoises, cannot handle even small increases in adult mortality
(Doak et al., 1994; U.S. Fish and Wildlife Service, 1994). In addition to tortoise collection, urban sprawl also has other negative effects on wildlife such the above mentioned fires, pets introductions, or road kills (Hansen et al., 2005; Boarman and Sazaki, 2006; SanzAguilar et al., 2011). These side effects, despite being less frequent
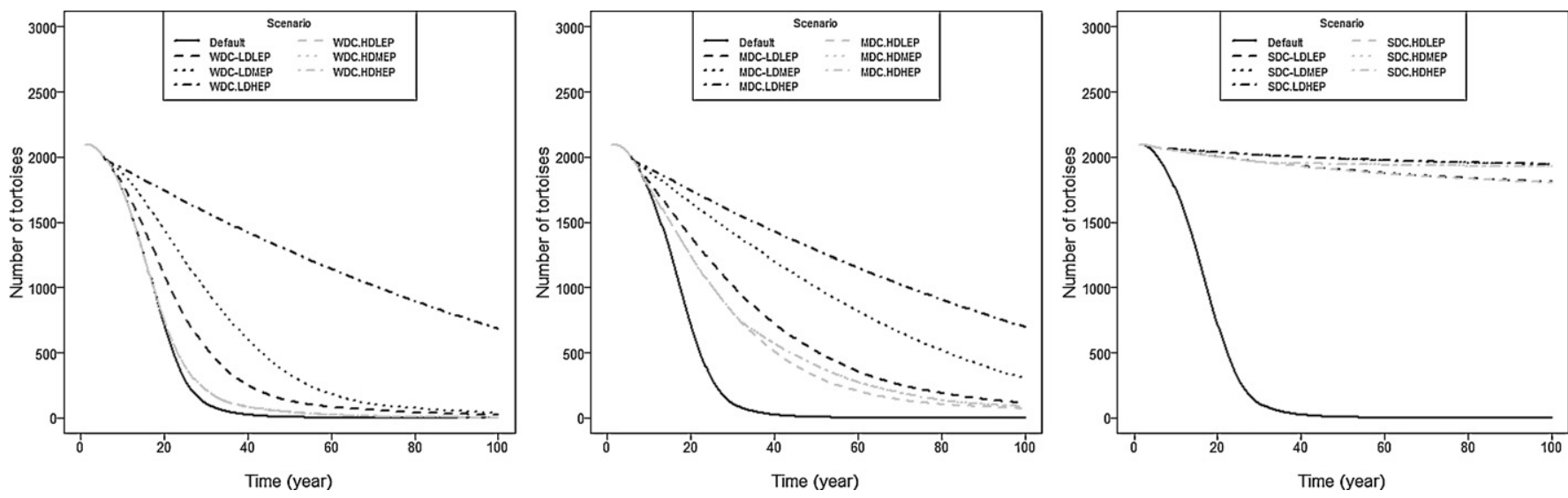

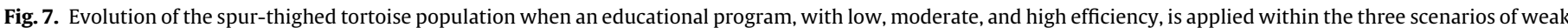

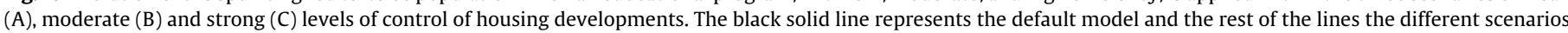
considered (Table 6 ). 
than pet collection, may have a significant concurrent negative impact on population viability, particularly when affected individuals are female adults (Doak et al., 1994; U.S. Fish and Wildlife Service, 1994).

New residents' concern about the environment (Manfredo et al., 2003) makes them a potentially receptive group for environmental education programs. However, accordingly with our results, an environmental education program by itself, with the aim of reducing the willingness of new residents to keep tortoises in captivity, does not seem very effective. The quality (or receptivity of local residents) and the speed with which the educational program is initialized are key factors in determining the effectiveness of the educational program. Our model could help in assessing the effectiveness of such educational programs. The scenarios simulation results suggest that the integration of policies limiting housing development's size and educational programs are the most effective way in reducing the impact of exurban development on tortoise populations.

In any case, our simulation results should be read cautiously and bearing in mind the underlying assumptions and restrictions considered. In order to keep our model as simple as possible, we have not considered stochasticity in any of the three submodels (spur-thighed tortoise dynamics, households dynamics and tortoise collection submodels). Introducing stochasticity in demographic models yields lower and more unpredictable population growth rates (Morris and Doak, 2002). In this sense, the spur-thighed tortoise dynamics submodel might overestimate population growth and thus underestimating the probability of extinction. However, the effects of concurrently introducing stochasticity in the three submodels are more unpredictable. Our model could include other variables that depend on the urbanization process, such as habitat quality and fragmentation and road kills. The inclusion of these variables may have an effect of the values of fecundity, reproduction, and survivor of tortoises, and would presumably accelerate the extinction process. On the other hand, the intensity of tortoise collections may change between years as tortoise detection levels change considerably depending on meteorological factors (DíazPaniagua et al., 2001; Freilich et al., 2000), and hence accelerate or decelerate the effects of collection. In addition, our model assumes the best initial situation, that is, a stable tortoise population in an optimal habitat and with no other factors affecting it (e.g. habitat fragmentation). Even in this situation, the impact of new residents' behavior is critical for the conservation of the local population. Finally, the social subsystem of our model could be improved to make it more reliable and include some more complex feedbacks, such us density dependence behavior on the proportion of people that want and collect tortoises.

Our model did not attempt to validate a particular real situation but rather it used theoretical assumptions and empirical data to understand the complex dynamics of a social-ecological system. The model structure proved useful and robust, as sensitivity analysis results showed, to respond to our research questions. The model showed a higher sensitivity to variation of the carrying capacity of wild tortoises. This means that the geographic area where housing development projects are planned is a key factor in assessing its impact on tortoise populations. In order to use our model for selecting managing decisions, it should be parameterized in a finer way. Changing the parameter values of our model could support the study of the effect of a specific population of the spur-thighed tortoises where exurban sprawl is being planned. Results can be used in the Environmental Impact Assessment (EIA) when deciding between locations of exurban sprawl and exurban intensity. In the same way, our model can be useful for other native species threatened by the behavior of residents of exurban areas. In this sense, pet collection of wildlife species is likely to be affecting other tortoise populations, such as those inhabiting areas of important exurban sprawl, for example other species of the genus Testudo in Europe and middle East (e.g. Beshkov, 1993; Perry and Dmiel, 1995; Livoreil, 2009) and Gopherus in United States (Bury et al., 1994).

In conclusion, our results highlight the importance of incorporating the human dimension for the management of wildlife species in exurban areas. Both direct (e.g. habitat loss) and diffuse effects (e.g. collection) of the development process ought to be considered in the urban planning. Accordingly to our results, a strong policy limiting housing development size, accomplished with an educational program, are required if wild populations of the spurthighed tortoise are to be conserved. Once housing development and pet collections have been controlled, translocation projects may be considered as a tool to recover local populations. The risk of this kind of measures (e.g. genetic mixing and disease spread) should be considered (Pérez et al., 2004).

\section{Acknowledgements}

We would like to thank all the people interviewed who gave their time to participate in this study. The interviews of new residents were funded by the Ministry of the Environment of Andalusia, the County Council of Almería. We acknowledge the Global Nature Foundation for allowing us to work in its Biological Reserve "Las Cumbres de la Galera". I. Pérez was partially founded by Fundación Séneca (Murcia, Spain). Nathan Rollins kindly reviewed the English text. Thanks to three anonymous reviewers for comments on a previous version of the manuscript. Finally, we thank the organizers of the 7th European Conference on Ecological Modelling for considering our presentation for this special number of Ecological Modelling.

\section{References}

Aliaga, I., 2008. Nuevos desarrollos urbanísticos en el campo de Murcia. Implicaciones territoriales y planeamiento municipal. Papeles Geografía 47-48, 5-24.

Anadón, J.D., Giménez, A., Martínez, M., Martínez, J., Pérez, I., Esteve, M.A., 2006 Factors determining the distribution of the spur-thighed tortoise Testudo graeca in southeast Spain: a hierarchical approach. Ecography 29, 339-346.

Anadón, J.D., Giménez, A., Ballestar, R., Perez, I., 2009. Evaluation of Local Ecological Knowledge as a method for collecting extensive animal abundance data. Conserv. Biol. 23, 617-625.

Anadón, J.D., Giménez, A., Ballestar, R., 2010. Linking local ecological knowledge and habitat modelling to predict absolute species abundance at large scales. Biodivers. Conserv. 19, 1443-1454.

Barlas, Y., 1996. Formal aspects of model validity and validation in system dynamics. Syst. Dynam. Rev. 12, 183-210.

Bautista, L.M., García, J.T., Calmaestra, R.G., Palacín, C., Martín, C.A., Morales, M.B. Bonal, R., Viñuela, J., 2004. Effect of weekend road traffic on the use of space by raptors. Conserv. Biol. 18, 726-732.

Bennett, V.J., Beard, M., Zollner, P.A., Fernández-Juricic, E., Westphal, L., LeBlanc, C.L 2009. Understanding wildlife responses to human disturbance through simulation modeling: a management tool. Ecol. Complex. 6, 113-134.

Bennett, V.J., Fernández-Juricic, E., Zollner, P.A., Beard, M.J., Westphal, L., LeBlanc C.L., 2011. Modelling the responses of wildlife to human disturbance: an evaluation of alternative management scenarios for black-crowned night-herons. Ecol. Model. 222, 2770-2779.

Berkes, F., Folke, C., 1998. Linking Social and Ecological Systems: Management Practices and Social Mechanisms for Building Resilience. Cambridge University Press, Cambridge, UK.

Beshkov, V.A., 1993. On the distribution, relative abundance and protection of tortoises in Bulgaria. Chelonian Conserv. Biol. 1, 53-62.

Boarman, W.I., Sazaki, M., 2006. A highway's road-effect zone for desert tortoises (Gopherus agassizii). J. Arid Environ. 65, 94-101.

Bury, R.B., Esque, T.C., DeFalco, L.A., Medica, P.A., 1994. Distribution, habitat use and protection of the desert tortoise in the Eastern Mojave Desert. Fish Wildlife Res. $13,57-72$.

Camarero, L., Cruz, F., González, M., del Pino, J.A., Oliva, J., Sampedro, R., 2009. La población rural de España. De los desequilibrios a la sostenibilidad social. In: Colección Estudios Sociales No. 27. Fundación La Caixa, Barcelona.

Cox, L., 2010. Conservation where half the world lives. Conserv. Biol. 24, 637-639.

Díaz-Paniagua, C., Keller, C., Andreu, A.C., 1997. Hatching success, delay of emergence and hatchling biometry of the spur-thighed tortoise, Testudo graeca, in south-western Spain. J. Zool. 243, 543-553.

Díaz-Paniagua, C., Keller, C., Andreu, A.C., 2001. Long term demographic fluctuations of the spur-thighed tortoise Testudo graeca in SW Spain. Ecography 24, 707-721. 
Díez de Revenga, E., Rodier, A., Picazo, H., 2006. La ordenación del territorio de la Región de Murcia: Estado actual de la materia. Consejo Económico y Social de la Región de Murcia, Murcia, Spain.

Doak, D.F., Kareiva, P., Kleptka, B., 1994. Modeling population viability for the desert tortoise in the western Mojave desert. Ecol. Appl. 4, 446-460.

European Environment Agency (EEA), 2006. Urban Sprawl in Europe. The Ignored Challenge. European Environment Agency No. 10/2006. European Environment Agency, Copenhagen, Denmark.

Fernández, R., 2006. El tsunami urbanizador español y mundial. Sobre sus causas y repercusiones devastadoras y la necesidad de prepararse para el previsible estallido de la burbuja inmobiliaria. Virus Editorial, Barcelona, Spain.

Freilich, J.E., Burnham, K.P., Collins, C.M., Garry, C.A., 2000. Factors affecting population assessments of desert tortoises. Conserv. Biol. 14, 1479-1489.

Frid, A., Dill, L., 2002. Human-caused disturbance stimuli as a form of predation risk Conserv. Ecol. 6, 11, URL: http://www.consecol.org/vol6/iss1/art11 (online).

Giménez, A., Anadón, J.D., Esteve, M.A., 2006. Estudios básicos sobre ecología y conservación de la tortuga mora (Testudo graeca L.) en la provincia de Almería. Junta de Andalucía.

Glaser, M., Krause, G., Ratter, B., Welp, M., 2008. Human-nature-interaction in the Anthropocene, potential of social-ecological system analysis. GAIA 17/1, 77-78.

Gössling, S., Kunkel, T., Schumacher, K., Zilger, M., 2004. Use of molluscs, fish, and other marine taxa by tourism in Zanzibar, Tanzania. Biodivers. Conserv. 13, 2623-2639.

Hailey, A., Loumbourdis, N.S., 1990. Population ecology and conservation of tortoises: demographic aspects of reproduction in Testudo Hermanni. Herpetol. J. 1, 425-434.

Hansen, A.J., Knight, R.L., Marzluff, J.M., Powell, S., Brown, K., Gude, P.H., Jones, K., 2005. Effects of exurban development on biodiversity: patterns, mechanisms, and research needs. Ecol. Appl. 15, 1893-1905.

IUCN, 2010. IUCN Red List of Threatened Species. Version 2010.4, www.iucnredlist.org (accessed 02.06.11).

Jepson, P., Ladle, R.J., 2005. Bird-keeping in Indonesia: conservation impacts and the potential for substitution-based conservation responses. Oryx 39, 1-6.

Jepson, P., Ladle, R.J., 2009. Governing bird-keeping in Java and Bali: evidence from a household survey. Oryx 43, 364-374.

Kluza, D.A., Curtice, R., Degraaf, R.M., 2000. Housing developments in rural New England: effects on forest birds. Anim. Conserv. 3, 15-26.

Langston, R.H.W., Liley, D., Murison, G., Woodfrield, E., Clarke, R.T., 2007. What effects do walkers and dogs have on the distribution and productivity of breeding European Nightjar Caprimulgus europaeus? Ibis 149, 27-36.

Liu, J., Dietz, T., Carpenter, S.R., Alberti, M., Folke, C., Moran, E., Pell, A.N., Deadman, P., Kratz, T., Lubchenco, J., Ostrom, E., Ouyang, Z., Provencher, W., Redman, C.L., Schneider, S.H., Taylor, W.W., 2007. Complexity of coupled human and natural systems. Science $317,1513-1516$.

Livoreil, K., 2009. Distribution of the Endangered hermann's tortoise Testudo hermanni hermanni in Var, France, and recommendations for its conservation. Oryx 43, 299-305.

Manfredo, M.J., Teel, T.L., Bright, A.D., 2003. Why are public values toward wildlife changing? Hum. Dimens. Wildlife 8, 287-306.

Mantecón, A., 2008. La experiencia del turismo. Un estudio sociológico sobre el proceso turístico-residencial. Icaria, Barcelona, Spain.

Miller, J.R., Hobbs, R.J., 2002. Conservation where people live and work. Conserv. Biol. 16, 330-337.
Mora, I., Sempere, R., Montesinos, A., Anadón, J.D., Giménez, A., 2006. Efectos de un incendio en la reproducción de la tortuga mora (Testudo graeca) en el sureste Ibérico/Reproduction of the spur-thighed tortoise after a fire in Southeast Spain. In: IX Congresso Luso-Espanhol, XIII Congreso Español de Herpetología, San Sebastián, Spain.

Morris, W.F., Doak, D.F., 2002. Quantitative Conservation Biology. Theory and Practice of Population Viability Analyses. Sinauer Associattes, Sunderland, MA

Olden, J.D., Poff, N.L., McKinney, M.L., 2006. Forecasting faunal and floral homogenization associated with human population geography in North America. Biol. Conserv. 127, 261-271.

O'Leary, R., Jones, D.N., 2006. The use of supplementary foods by Australian magpies Gymnorhina tibicen: implications for wildlife feeding in suburban environments. Aust. Ecol. 31, 208-216.

Pérez, I., Giménez, A., Anadón, J.D., Martínez, M., Esteve, M.A., 2002. Patrones de actividad estacional y diaria de la tortuga mora (Testudo graeca graeca) en el sureste de la Península Ibércia. Anales de Biología 24, 55-65.

Pérez, I., Giménez, A., Sánchez, J.A., Anadón, J.D., Martínez, M., Esteve, M.A. 2004. Non-commercial collection of spur-thighed tortoises (Testudo graeca graeca): a cultural problem in a southeast Spain. Biol. Conserv. 118 $175-181$.

Pérez, I., Giménez, A., Pedreño, A., 2010. Dimensión social de la conservación de la fauna: la tortuga mora. Editum. Ediciones de la Universidad de Murcia, Murcia, Spain.

Pérez, I., Giménez, A., Pedreño, A., 2011. A qualitative examination of the social practices and representations towards a species of endangered tortoise. Wildlife Res. 38, 323-329.

Pérez, I., Giménez, A., Pedreño, A., in press. Impacts of exurban sprawl: the effects of the perceptions and practices of new residents toward the spur-thighed tortoise Testudo graeca. Wildlife Soc. Bull.

Perry, G., Dmiel, R., 1995. Urbanization and sand dunes in Israel - direct and indirect effects. Isr. J. Zool. 41, 33-41.

Peterson, M.N., Lopez, R.R., Laurent, E.J., Frank, P.A., Silvy, N.J., Liu, J., 2005. Wildlife loss through domestication: the case of endangered key deer. Conserv. Biol. 19, 939-944.

Riley, S.P.D., Busteed, G.T., Kats, L.B., Vandergon, T.L., Lee, L.F.S., Dagit, R.G., Kerby, J.L Fisher, R.N., Sauvajot, R.M., 2005. Effects of urbanization on the distribution and abundance of amphibians and invasive species in southern California streams. Conserv. Biol. 19, 1894-1907.

Riley, S.P.D., Sauvajot, R.M., Fuller, T.K., York, E.C., Kamradt, D.A., Bromley, C., Wayne, R.K., 2003. Effects of urbanization and habitat fragmentation on bobcats and coyotes in southern California. Conserv. Biol. 17, 566-576.

Sanderson, E.W., Huron, A., 2011. Conservation in the city. Conserv. Biol. 25 421-423.

Sanz-Aguilar, A., Anadón, J.D., Giménez, A., Ballestar, R., Graciá, E., Oro, D., 2011 Coexisting with fire: the case of the terrestrial tortoise Testudo graeca in Mediterranean shrublands. Biol. Conserv. 144, 1040-1049.

Theobald, D.M., 2005. Landscape patterns of exurban growth in the USA from 1980 to 2020 . Ecol. Soc. $10,32$.

U.S. Fish and Wildlife Service, 1994. Desert tortoise (Mojave population) Recovery Plan. U.S. Fish and Wildlife Service, Portland, Oregon.

Ventana Systems, 1998. VENSIM ${ }^{\circledR}$, Ventana Simulation Environment. Reference Manual, Harward. 